\title{
Correction to: Clinical characterization of a Korean case with 3p25 deletion
}

Hye Jin Lee, Ja Hye Kim¹, Ja Hyang Cho', Jin-Ho Choi ${ }^{1}$, and Han-Wook Yoo ${ }^{1,2, *}$

${ }^{1}$ Department of Pediatrics, ${ }^{2}$ Medical Genetics Center, Asan Medical Center Children's Hospital, University of Ulsan College of Medicine, Seoul, Korea

\section{J Genet Med 2014;11(1):36-39 (http://dx.doi.org/10.5734/JGM.2014.11.1.36)}

This correction is being published to correct the authors' names in above article. The authors would like to announce that the fourth author of this article should be deleted. The authors apologize for any inconvenience this may cause.

\section{Before correction}

Hye Jin Lee', Ja Hye Kim', Ja Hyang Cho', Beom Hee Lee, ${ }^{1,2}$, Jin-Ho Choi ${ }^{1}$, and Han-Wook Yoo ${ }^{1,2, *}$

\section{After correction}

Hye Jin Lee', Ja Hye Kim¹, Ja Hyang Cho', Jin-Ho Choi' , and Han-Wook Yoo ${ }^{1,2, *}$

*Corresponding author: Han-Wook Yoo, M.D., Ph.D.

Department of Pediatrics, Asan Medical Center Children's Hospital, University of Ulsan College of Medicine, 88 Olympic-ro 43-gil, Songpa-gu, Seoul 138736, Korea.

Tel: +82-2-3010-3374, Fax: +82-2-473-3725, E-mail: hwyoo@amc.seoul.kr

Conflict of interest: We declare that we do not have any conflicts of interests.

(c) This is an open-access article distributed under the terms of the Creative Commons Attribution Non-Commercial License (http://creativecommons.org/licenses/by-nc/3.0/) which permits unrestricted non-commercial use, distribution, and reproduction in any medium, provided the original work is properly cited. 